\title{
METHODS IN TAXONOMY
}

$\mathrm{O}$ N March 31 the Systematics Association held a oneday demonstration meeting at the British Museum (Natural History). This meeting attracted forty-five exhibits concerned with botanical, zoological and palaeontological taxonomy. The exhibitors were drawn from the British Museum (Natural History), University of Cambridge, the Imperial College of Science and Technology, the National Institute of Oceanography, the Nature Conservancy, New York State College of Agriculture, University of Oxford, Rothamsted Experimental Siation, the Royal Botanic Gardens, Kew, the University of Leeds and the University of Manchester.

After a welcome had been extended by the Director of the Museum, the proceedings were opened by Prof. P. C. Sylvester-Bradley, president of the Association. Prof. Bradley heralded the meeting as a contribution to "the biological dialogue". He suggested that the controversy that had sprung up a few years ago between cell biologists (who stressed the unity of life) and systematists (who investigated the diversity of life) had now entered a constructive phase. In most universities and most schools of biology a debate was in progress which promised to initiate research in the fruitful field that lies in the region of overlap between cell biology and comparative biology. In investigating the diversity of life, taxonomy answers 'the what' of comparative biology, and systematics 'the how'. New methods in taxonomy supply an essential vitality to this biological dialogue.

The exhibits at the meeting were organized under five headings ("Collecting", "Preparation and Maintenance", "Examination and Extraction of Information", "Analysis and Synthesis of Information", and "Presentation and Dis. semination of Results") and were laid out so that visitors were guided around the exhibition in this sequence. As the catalogue of exhibits suggested, this sequential classification-while representing an ideal picture of orderly progress through a programme of taxonomic researchcannot be assumed to represent the usual pattern of taxonomic work; nor are the five stages necessarily clearly recognizable.

Collecting is the process of sorting organisms from their environmont, and, in so doing, concentrating them. The eight exhibits in the section on collecting illustrated the variety of ways in which this can be achieved. In most groups mechanical devices can increase the efficiency of collecting. These devices either exploit the behaviour of the organism or else overcome behaviour and the speed of movem 3 t. To the first group of aids belong equipment for the extraction of microarthropods from soil and the attraction of insects to light; to the second group belong the great variety of stationary and moving traps and nets.

In many instances neither the organisms nor the nets or traps are visible to the collector, and in these cases control of sampling is difficult to achieve; but it is inter. esting to note that only where collecting takes place in large water-masses, such as lakes or the sea, is it feasible to monitor the equipinent and thus know exactly how it is behaving. Monitoring apparatus such as that used at sea for tracking the behaviour of nets are scarcely worth devising for collecting in other environments such as streams or dense herbage. A particular advantage of collecting devices lies in the fact that if the behaviour of the equipment is known accurately it becomes easy to sample quantitatively. For the most sophisticated taxonomy, giving the most highly predictive results, quantitative sampling is essential.
Sorting organisms from their environment does not itself produce useful collections, and without careful labelling and annotation even the finest collections are of limited use to the taxonomist. Great care and effort have gone into the preparation of labels which can carry, in standardized forms, information essential to the taxonomist. Even the lay-out and type-face of printed labels are important, having significance for the rapid sorting and selection of prepared specimens. Probably in no branch of biology has this been more clearly recognized than in botany. But, however clearly and neatly labels may be designed and printed, it is still necessary to ensure that the collector completes them intelligibly and permanently in the field. Collection labels are best accompanied by sets of hard-and-fast rules for their use.

While even quantitative sampling of the larger plants may require no elaborate apparatus, botanists face far greater difficulties in the preservation of their material in the field than do most zoologists and palmeontologists. Skinning or the rapid chemical fixation of animals do not compare with the lengthy and elaborate processes of drying, mounting and pressing of fragile plants-all processes which must be completed perfectly in the field if specimens are to be of value later. In contrast, the field preservation of fossils-while sometimes essential-is not always necessary. More often the palaeontologist is faced in the laboratory with the greatest difficulty in separating the fossils from their environment. Because of this the chemical development and mechanical separation of fossils are fields of highly developed technology.

The second section of the exhibition, concerned with the preparation and maintenance of organisms, was necessarily mostly concerned with methods which come within the domain of museum curation. Of particular interest were the exhibits which demonstrated the advantages to biology of the recent rapid advances in the fields of plastics and polymer resin technology, which allow impregnation and imbedding of such diverse structures as fossil and recent bones, plants and invertebrates. These newly available compounds and their properties have brought almost to the level of mass-production standards of mounting, dissecting, sectioning and display which were hitherto reserved for special exhibits, and which could be achieved only with the greatest labour. While some of these plasties and resins are useful both as preservative and preparatory media, other new compounds have been developed for the bulk preservation and storage of organisms. Perhaps the most important of these is phenoxetol, which, with its good properties as a preserva. tive, its low price, absence of smell, and avoidance of fire risks, promises to be a useful substitute for alcohol and formalin in large collections. Another significant innovation, increasingly used in museums, is the practice of freeze-drying whole specimens, when colour, shape, texture and posture of even quite large vertebrates can be most amazingly retained.

A specimen preserved for several decades by any technique is of little use if the labels that accompany it have deteriorated. In recent years much research has been done to determine the qualities of paper and ink which will remain intact and unfaded for many years in both herbarium and spirit store, despite wide fluctuations in temperature, humidity, and other features of the environment. Furthermore, not only must labels not deteriorate, but in design and layout they must be as clear in the store as they are to the collector in the field. 
Surprisingly, perhaps, few exhibits in this section dealt in detail with the administration of large collections. All the more interesting therefore were the exhibits of the curation of extensive insect and mammal collections, which demonstrated the importance to taxonomic research of type specimens, named series, and the most effective physical arrangements of animals of widely varying shapes and sizes. The proper curation of large collections requires speedy and accurate storage and retrieval, not only of objects but also of information about the objects. This presents a problem that is further complicated by the difficulty of deciding how much information the objects themselves display and how much should be documented. As exhibits in the sections of the demonstration on analysis and synthesis and presentation and dissemination revealed, this complication is becoming increasingly troublesomo. Small collections made for special research purposes appear to be readily suitable for documentation with punched cards, special maps and other recent innovations.

The exhibits displayed in the section dealing with examination and extraction of information were all concerned with methods of obtaining information not immediately detectable without the help of instrumentation, and this section, porhaps more than any other in the demonstration, showed how very many developments in the physical sciences are rapidly turned to their advantage by taxonomists. 'Two oxhibits of striking electronmicrographs complemented nicely a demonstration of the range of light microscope techniques. X-ray illustrations of skeletal structures, moulds of leaf surfaces, and electronic recordings of insect sounds were the themes of other exhibits showing exploitation of techniques which might be thought to belong solely within the fields of the physical sciences.

Demonstrations of the uses to taxonomists of paper chromatography, electrophorotic separation of proteins, and a varioty of serological techniques indicated th $\theta$ increasing significance to taxonomy-especially of $\gamma$ taxonomy - of advances in biochemistry.

Many techniques and instruments can provide the taxonomist with assessable information, and a point which the exhibits in this section underlined is that no one technique, whether simple or the ultimate in sophistication, can be held to be the most useful. It was perhaps unfortunate that there was no exhibit which domonstrated the usefulness in taxonomy of the unaided human senses and such simple instruments as callipers.

Just as the significance to taxonomy of the human senses is not easy to display, so the vital importanco of human mental processes of induction and deduction did not lond thomselves readily to demonstration in the section on analysis and synthesis. The ever-increasing use of mathematical and geometrical methods of analysis and synthesis in taxonomy was demonstrated by the use of geometrical transformations of structure and a wide array of methods of multivariate analysis. The development of these last techniques, which is closely linked with advances in computer technology, allows taxonomists to take on research problems which, in the past, would have required many years for completion-if indeed they could have beon contemplated - but which can nowadays be completed in a few weeks or months. Numerical treatment of taxonomic data is still a subject of much controversy; but there can be no doubt that its use encourages taxonomists to regard the organisms with which they deal as parts of populations. This is essential for progress in some areas of taxonomy; but what is urgently needed, if numerical taxonomy is to become an accopted tool of routine identification and classification, is proof that the labour of collecting the vast quantities of data required for the statistics is rewarded by greatly increased usofulnoss of the results.

Numerical methods of analysis and synthesis may allow taxonomists to handle rapidly large amounts of data; but, as the section concerned with presentation and dissemination of results showed all too clearly, biological data are not the only items which are accumulating faster than they can be handlod by traditional methods. Collections of organisms are growing rapidly all the time, and will continue to grow at a high rate for many years to come. Every specimen is a source of useful information, and so, ideally, every specimen should be easily retrieved from the collection, while the information which accompanies it should be readily available. Unfortunately, because of the continued growth of collections, and because the theories and practice of information storage and retrieval are still in an carly stage of development, probably all institutions which maintain large collections are faced with apparently insuperable problems of management. While collections the items of which can be counted in hundreds can be adequately controlled and used by means of written guides and indices, theso time-honoured methods cannot be efficient where collections must be numbered in tens or hundreds of thousands. Considerable thought is now going into the design of machinery and procedures which can deal efficiently and rapidly with the documentation and control of large collections. If these efforts are successful the exchange of information and material between taxonomists could be greatly improved.

Not only are collections of organisms expanding at a tremendous rate but the volume of published work which each taxonomist must review grows every year. Collection management and the control of published results have many problems in common, and many of the same principles are employed to devise information storago and retrieval aids in both ficlds. However, some problems of bibliography control can be solved more easily than can their counterparts in collection management. Uniform high standards of illustration, typography and layout can be demanded, as can condensation of text, but organisms to be stored will always be highly heterogeneous in the amount of information which they reveal on casual inspection and in their storage requirements. It was clear from several exhibits in this section that much taxonomic publication could be standardized to allow efficient storage and easy perusal. Ideas differ as to the best ways of achieving these aims, and it is to be hoped. that some measure of agreoment will be reached soon. Otherwise the taxonomist will find himself forced to read yet more journals with different and conflicting methods of prosentation.
WiLimam G. Fry

\section{TELEVISION AND RADIO IN BRITAIN}

$I^{\mathrm{N}}$ $\mathrm{N}$ opening a debato on broadcasting in the House of Commons on May 13, Sir Peter Rawlinson pressed for information as to the Government's plans for television and advocated that the new fourth channel should bo devotod to commercial television. As regards sound broadcasting, he thought that this was the appropriate time to encourage local broadcasting and the right solution was to be found in Iow-range local broadeasting stations. In replying for the Government, the PostmasterGeneral, Mr. Wedgwood Benn, said that it was essential bofore taking a decision on tho allocation of the fourth channel that we should be clear as to what purposes the fourth channel should be required to meet. Educational broadeasting was very closoly tied to the question of the 